\title{
Preclinical Evaluation of Vaccines to Treat Opioid Use Disorders: How Close are We to a Clinically Viable Therapeutic?
}

\author{
E. Andrew Townsend ${ }^{1}$ (D) Matthew L. Banks ${ }^{1}$ D
}

Published online: 4 April 2020

(c) Springer Nature Switzerland AG 2020

\begin{abstract}
The ongoing opioid crisis, now into its second decade, represents a global public health challenge. Moreover, the opioid crisis has manifested despite clinical access to three approved opioid use disorder medications: the full opioid agonist methadone, the partial opioid agonist buprenorphine, and the opioid antagonist naltrexone. Although current opioid use disorder medications are underutilized, the ongoing opioid crisis has also identified the need for basic research to develop both safer and more effective opioid use disorder medications. Emerging preclinical evidence suggests that opioid-targeted vaccines or immunopharmacotherapies may be promising opioid use disorder therapeutics. One premise for this article is to critically examine whether vaccine effectiveness evaluated using preclinical antinociceptive endpoints is predictive of vaccine effectiveness on abuse-related endpoints such as drug self-administration, drug discrimination, and conditioned place preference. A second premise is to apply decades of knowledge in the preclinical evaluation of candidate small-molecule therapeutics for opioid use disorder to the preclinical evaluation of candidate opioid use disorder immunopharmacotherapies. We conclude with preclinical experimental design attributes to enhance preclinical-to-clinical translatability and potential future directions for immunopharmacotherapies to address the dynamic illicit opioid environment.
\end{abstract}

\section{Key Points}

Vaccine effectiveness should be assessed in terms of opioid agonist potency shifts.

Vaccine effectiveness on a preclinical endpoint should be directly compared to effectiveness with naltrexone or buprenorphine treatment.

Vaccine effectiveness should be evaluated on preclinical endpoints that are analogous to clinical opioid use disorder endpoints to enhance translational concordance.

Matthew L. Banks

mbanks7@vcu.edu

1 Department of Pharmacology and Toxicology, Virginia Commonwealth University, 410 North 12th St, Box 980613, Richmond, VA 23298, USA

\section{Rationale for Opioid-Targeted Vaccines as Candidate Opioid Use Disorder Medications}

Although the opioid crisis has been mostly documented in North America, this ongoing crisis represents a global public health issue. For example, the latest estimates from the United Nations Office on Drugs and Crime put the number of opioid users at 53 million and an increase of $56 \%$ from previous estimates [1]. Currently, there are three medications clinically utilized in opioid use disorder (OUD) treatment. These medications include the mu-opioid receptor (MOR) antagonist naltrexone, the MOR partial agonist buprenorphine, and the full MOR agonist methadone [2]. These medications decrease the risk of opioid-related fatality [2, 3], and both methadone and buprenorphine are among the World Health Organization's List of Essential Medicines [4]. However, limitations of these medications have also been identified. For instance, the use of naltrexone requires the patient to be fully detoxified from opioids, otherwise risking the precipitation of opioid withdrawal signs and relapse [5]. In addition, patient compliance for naltrexone in both oral and depot-injection formulations has been problematic [6]. As for MOR agonist treatments (i.e., buprenorphine, 
methadone), clinical limitations are mostly related to abuse liability concerns $[7,8]$, which restricts their clinical availability and contributes to medication underutilization. In addition, buprenorphine and methadone can also produce opioid dependence as a result of their MOR agonist activity, and treatment cessation would result in the emergence of opioid withdrawal signs [9]. In summary, the limitations of current OUD therapeutics highlight the need for the development and evaluation of novel medications that retain effectiveness and minimize the limitations of current OUD treatments.

One strategy under investigation for OUD treatment includes opioid-targeted vaccines or immunopharmacotherapies. The fundamental components of an opioid-targeted vaccine are the hapten, the immunogenic carrier molecule, and adjuvants [10-12]. The hapten is a molecule that is structurally similar to the target opioid (e.g., oxycodone, heroin, or fentanyl) with the addition of a "linker" structure. This linker structure facilitates the conjugation of the hapten to an immunogenic carrier molecule (e.g., adenoviruses, nanoparticles, or foreign proteins). This immunoconjugate is formulated with adjuvants (e.g., alum or Toll-like receptor agonists) intended to further stimulate the immune response and all these components collectively constitute a vaccine. Upon vaccine administration, the subject's immune system generates antibodies against the hapten that circulate in the periphery. If a vaccinated subject is exposed to the targeted opioid, the antibodies should bind to the target opioid, generating an antibody-opioid complex that should be unable to pass through the blood-brain barrier. This peripherally sequestered opioid should be unable to interact with centrally located opioid receptors that mediate the abuse-related behavioral effects of opioids $[13,14]$. The net effect is the potency of the opioid to produce centrally mediated effects is decreased and more opioid would be needed to overcome the antibodies and cross the blood-brain barrier to activate centrally located opioid receptors. Therefore, this antibodymediated decrease in opioid potency mimics potency shifts produced by conventional MOR antagonists (e.g., naltrexone), and has resulted in opioid-targeted vaccines being referred to sometimes as "immunoantagonists."

Opioid-targeted vaccines have been hypothesized to confer several advantages over currently used OUD treatments (see [12] for a recent commentary). A primary advantage of opioid-targeted vaccines over traditional pharmacotherapies is that anti-opioid antibodies have no known interactions with receptors or proteins in the brain or periphery, suggesting that the antibodies would confer a low risk of receptor-mediated side effects. Prototypic local vaccine reactions (e.g., pain, swelling, or erythema) would be predicted. Moreover, the absence of MOR interactions would alleviate abuse liability concerns for MOR agonist OUD treatments (i.e., methadone, buprenorphine) and blockade of endogenous opioid signaling by antagonist OUD treatments (i.e., naltrexone). Furthermore, vaccine-induced antibodies are hypothesized to have long half-lives, which would be expected to prolong inter-administration intervals and may enhance compliance or retain therapeutic effectiveness longer following a missed dose compared with current depot naltrexone or buprenorphine formulations. Finally, haptens that resemble illicit opioids, such as heroin, would not interact with structurally dissimilar opioid agonists for either pain management (e.g., oxycodone) or OUD (e.g., buprenorphine or methadone) in a vaccinated subject. Combination vaccine plus depot naltrexone or buprenorphine treatment approaches are particularly attractive potential OUD therapeutics. The use of buprenorphine or methadone in combination with depot naltrexone would be more complicated, but possible [15].

\section{Preclinical Methods for Evaluating Vaccine Effectiveness}

Because of the potential clinical advantages described above, preclinical research on immunopharmacotherapies has been reinvigorated over the past decade. Abused opioid agonists produce a constellation of behavioral (e.g., reinforcement) and physiological (e.g., respiratory depression) effects. Opioid-targeted vaccines would be clinically viable treatments to address the abuse-related behavioral effects of opioids related to OUD, whereas opioid-targeted monoclonal antibodies would be clinically viable treatments to address the physiological effects of opioids related to lethal respiratory depression $[10,16]$. This article focuses on opioid vaccines and reviews the literature regarding preclinical methods to efficiently evaluate vaccine effectiveness and how predictive these preclinical methods are to clinical OUD outcomes.

The two most frequently utilized preclinical endpoints for evaluating opioid vaccine effectiveness are opioid-induced antinociception and intravenous opioid self-administration. For opioid-induced antinociception endpoints, a research subject is exposed to a noxious stimulus (e.g., a mouse's tail dipped into water heated to $50{ }^{\circ} \mathrm{C}$ ) and the latency of the mouse to remove its tail from the heated water is recorded. If the mouse is administered an opioid agonist (e.g., morphine), the latency or time before the mouse removes its tail increases relative to baseline and is indicative of antinociceptive effect $[17,18]$. In fact, one of the first preclinical studies evaluating immunopharmacotherapy approaches for opioids used this type of procedure. Mice immunized with a fentanyl-bovine gamma globulin conjugate in complete Freund's adjuvant showed an attenuated antinociceptive effect of fentanyl compared with mice that only received complete Freund's adjuvant [19]. Since the 1970s, preclinical evaluation of vaccine effectiveness to attenuate opioid-induced 
antinociception has continued. Experimental advantages include relatively high throughput with minimal animal training by the experimenter and minimal equipment (i.e., hot plate or water bath and stopwatch) compared to drug self-administration procedures that will be described next. However, the paucity of empirical data to support translational predictive validity of preclinical antinociceptive endpoints to other preclinical endpoints (i.e., drug self-administration) that have demonstrated predictive validity [20-22] or human laboratory and clinical trial endpoints remains a weakness in the utility of this preclinical endpoint to screen candidate OUD immunopharmacotherapies.

Intravenous drug self-administration is considered one of the most translationally relevant preclinical procedures to assess candidate medication effectiveness (see [20-23] for review). Although there are numerous variations of drug self-administration procedures, there are three basic components (i.e., three-term contingency) [24]. For example, a research subject (e.g., rat or monkey) is implanted with an intravenous catheter (e.g., jugular or femoral) and placed in an operant chamber with a syringe pump, a manipulandum (e.g., lever) and a stimulus light. When the stimulus light (i.e., discriminative stimulus) is turned on, pressing the lever (i.e., response) will lead to the delivery of an intravenous drug injection (i.e., consequent stimulus), completing the three-term contingency. If the drug dose functions as a positive reinforcer, then the delivery of the drug injection will increase the rate of responding on the lever. Candidate medications, such as vaccines, can then be evaluated for effectiveness to reduce drug-taking behavior.

One year earlier than the fentanyl vaccine study in mice described above, the first study evaluating an immunopharmacotherapy approach on intravenous drug self-administration was published. In this study, a single rhesus monkey was trained to self-administer heroin $(0.006 \mathrm{mg} / \mathrm{kg} /$ infusion $)$ and cocaine $(0.1 \mathrm{mg} / \mathrm{kg} /$ infusion $)$ across alternating sessions under a fixed-ratio (FR) 10 schedule of reinforcement [25]. The monkey was then vaccinated with a morphine-6-hemisuccinyl-bovine serum albumin conjugate over a 20-week period before heroin and cocaine self-administration sessions were resumed. Rates of heroin self-administration extinguished to saline levels, whereas rates of cocaine selfadministration were similar to pre-vaccination levels demonstrating a degree of vaccination selectivity. Only when the unit heroin dose was increased to $0.1 \mathrm{mg} / \mathrm{kg} /$ infusion did rates of responding increase over saline levels. Unfortunately, a complete heroin dose-response function was not determined before or after vaccination, thus precluding the ability to quantify the magnitude of the immunizationinduced potency shift.

In a follow-up study, two rhesus monkeys self-administered heroin $(0.012 \mathrm{mg} / \mathrm{kg} /$ infusion $)$ and cocaine $(0.2 \mathrm{mg} /$ $\mathrm{kg} /$ infusion) during alternating sessions under an FR 10 schedule [26]. These animals were passively immunized with antibodies generated in other rhesus monkeys administered the morphine-6-hemisuccinyl-bovine serum albumin conjugate. Rates of heroin self-administration increased twoto three-fold during the session following immunization, with effects dissipating over the course of 3 weeks. Rates of cocaine self-administration were not altered demonstrating vaccine selectivity. Notably, vaccination effects were similar to a halving of the unit heroin dose $(0.006 \mathrm{mg} / \mathrm{kg} /$ infusion $)$ or pretreatment with the MOR antagonist naloxone [26]. Because of the translational predictive validity of drug selfadministration procedures in evaluating candidate medications for substance use disorder, these procedures continue to be utilized to evaluate candidate vaccines.

\section{Vaccine Effects on Drug Self-Administration}

Opioid abuse and OUD are behaviors that are learned through the three-term contingency described above where the presence of a drug dealer (i.e., discriminative stimulus) signals to an individual that exchanging money (i.e., response) will result in the delivery of an opioid (i.e., consequent stimulus). The progression of initial opioid abuse to OUD can be categorized into three phases. The first phase is acquisition of the drug self-administration behavior. The second phase is maintenance of the drug self-administration behavior once learned or acquired. The last phase is relapse or resumption of drug self-administration behavior following a period of abstinence or extinction. Preclinical drug selfadministration procedures can then be utilized to evaluate vaccine effectiveness across these different phases of abused drug exposure and learning.

\subsection{Vaccine Effects on the Acquisition of Opioid Self-Administration}

In these studies, drug-naïve subjects are implanted with intravenous catheters and placed into an operant chamber where pressing a lever in the presence of a light will result in the intravenous delivery of a unit dose of opioid. In acquisition studies, opioid vaccines are evaluated for their ability to block or slow acquisition rates of drug self-administration behavior. The hypothesis would be that if the vaccine slowed or disrupted learning of the contingencies between the discriminative stimulus, operant response, and consequent stimulus, the opioid would not function as a reinforcer and the research subject would not acquire drug self-administration behavior. Conceptually, these preclinical experiments would model the clinical situation of prophylactic vaccination in vulnerable individuals prior to the initiation of opioid abuse and progression to OUD. 
Four studies have evaluated vaccine effectiveness on the acquisition of opioid self-administration. In one study, a heroin vaccine significantly decreased the proportion of rats meeting acquisition criteria for $0.06-\mathrm{mg} / \mathrm{kg} / \mathrm{infu}-$ sion heroin self-administration compared with the control group, whereas a morphine vaccine was ineffective [27]. 3,6-Diacetylmorphine (heroin) is rapidly de-acetylated in the periphery to the active metabolite 6-acetylmorphine in rats [28], monkeys [29], and humans [30]. 6-Acetylmorphine can then be de-acetylated to morphine in the periphery or can readily cross the blood-brain barrier and be de-acetylated to morphine in the central nervous system [31]. This study would suggest that vaccines targeting heroin or 6-acetylmorphine would be more effective than those targeting morphine. Importantly, neither vaccine altered acquisition of sweetened solution self-administration demonstrating a measure of behavioral selectivity. Similar results have also been reported with an oxycodone-targeted vaccine [32]. A third study evaluated an oxycodone vaccine under more rigorous conditions by determining vaccine effectiveness to alter acquisition of oxycodone self-administration using two different oxycodone doses (0.06 and $0.15 \mathrm{mg} / \mathrm{kg} /$ infusion) [33]. The oxycodone vaccine blunted acquisition of $0.06 \mathrm{mg} /$ $\mathrm{kg}$ /infusion oxycodone self-administration such that $60 \%$ of vaccinated rats met acquisition criteria compared with $100 \%$ of control rats met acquisition criteria. However, the oxycodone vaccine failed to significantly decrease acquisition of $0.15 \mathrm{mg} / \mathrm{kg} / \mathrm{infusion}$ oxycodone self-administration compared to control animals. These later results highlight the importance of evaluating vaccine effectiveness across a broad range of abused drug doses and also the potential limitations of vaccines as prophylactic treatments for substance use disorders.

In contrast to the three studies described above, a fourth study reported that a morphine vaccine increased acquisition rates of heroin $(0.06 \mathrm{mg} / \mathrm{kg} /$ infusion $)$ self-administration [34]. Although counter intuitive, these results provide evidence that immunopharmacotherapies decrease the potency of the target drug of abuse. Rates of drug self-administration behavior under FR schedules of reinforcement display a prototypic, inverted U-shaped dose-effect function. The reasons why rates of drug self-administration under FR schedules display this inverted U-shaped dose-effect function are discussed in more detail below (see Sect. 3.2). However, a vaccine-induced reduction in heroin potency on the descending limb of the heroin self-administration dose-effect function would manifest as an increase in rates of heroin self-administration and be consistent with opioid antagonist treatment effects of single opioid doses on the descending limb [35].

In summary, these studies provide some evidence that immunopharmacotherapies can decrease acquisition rates of opioid self-administration under certain experimental conditions, but not others [34]. The necessity of opioid-naïve subjects imposes limitations in experimental throughput to characterize potency shifts and any behavioral measures of vaccine selectivity. In addition, interpretation of these published studies is complicated by the absence of comparison with a positive control. Moreover, there is no scientific consensus on what would constitute a positive control treatment for preclinical drug self-administration acquisition studies. For example, would naltrexone maintenance or social interaction $[36,37]$ function as a positive control for these acquisition studies? In addition, there are also ethical considerations in the clinical deployment of a prophylactic vaccine for OUD that is beyond the scope of this article (Table 1).

\subsection{Vaccine Effects on Maintenance of Opioid Self-Administration}

In these studies, the experimental subjects have already acquired opioid self-administration and vaccines are evaluated for effectiveness to disrupt ongoing rates of drug selfadministration behavior. However, before discussing the published literature determining vaccine effectiveness to attenuate opioid self-administration, one important consideration is the unit dose(s) of opioid used in these experiments and how this influences the interpretation of vaccine effectiveness to alter drug self-administration. For example, systematic manipulation of the unit drug dose under a FR or progressive-ratio (PR) schedule of reinforcement will result in a prototypic "inverted-U" shaped graph of reinforcement rates as a function of unit drug dose (for review, see [38]). The leftward portion of the inverted-U (i.e., the ascending limb) captures dose-dependent increases in drug self-administration rates. The highest rate of responding is observed at the peak of this function, and higher unit drug doses engender progressively lower rates of responding (i.e., descending limb). Why would rates of drug self-administration decrease as the drug dose increases above some peak level? As in other pharmacological domains, inverted U-shaped dose-effect functions indicate that multiple or opposing drug effects are being integrated into a common dependent measure. For example, measures of drug self-administration rate can be influenced not only by the reinforcing effects of the drug (which would have the effect of increasing rates), but also other effects of the self-administered drug that can either increase or decrease rates of responding (e.g., drug effects that enhance or impair motor competence). We have conceptualized and referred these other drug effects as "reinforcement-independent rate-altering effects" [39, 40]. Therefore, the examination of vaccine effectiveness on a single-unit drug dose under FR or PR schedules of reinforcement may result in a decrease, increase, or no change in rates of reinforcement, depending on (1) the position of that single-unit drug dose on the dose-effect function and (2) the magnitude of the vaccine-induced potency shift. Without 
Table 1 Summary of published preclinical studies reporting on vaccine effectiveness on intravenous drug self-administration (SA) endpoints. $\downarrow$ Decrease, $\uparrow$ increase, $\varnothing$ no effect

\begin{tabular}{|c|c|c|c|c|c|}
\hline Drug & Vaccine & Species and sex & Primary endpoint & Main effect & References \\
\hline \multicolumn{6}{|c|}{ Acquisition of opioid self-administration } \\
\hline Morphine & $\begin{array}{l}\text { Morphine hapten/KLH } \\
\text { conjugate }\end{array}$ & Male Wistar rats & $\begin{array}{l}\text { Acquisition of heroin SA } \\
(60 \mu \mathrm{g} / \mathrm{kg} / \text { infusion), fixed } \\
\text { ratio }\end{array}$ & $\varnothing$ & {$[27]$} \\
\hline Heroin & $\begin{array}{l}\text { Heroin hapten/KLH con- } \\
\text { jugate }\end{array}$ & Male Wistar rats & $\begin{array}{l}\text { Acquisition of heroin SA } \\
(60 \mu \mathrm{g} / \mathrm{kg} / \mathrm{infusion}), \text { fixed } \\
\text { ratio }\end{array}$ & $\downarrow$ & {$[27]$} \\
\hline Heroin & $\begin{array}{l}\text { Morphine hapten/KLH } \\
\text { conjugate }\end{array}$ & Male Holtzman rats & $\begin{array}{l}\text { Acquisition of heroin SA } \\
(60 \mu \mathrm{g} / \mathrm{kg} / \text { infusion }), \text { fixed } \\
\text { ratio }\end{array}$ & $\uparrow$ & {$[32]$} \\
\hline Oxycodone & $\begin{array}{l}\text { Oxycodone hapten/KLH } \\
\text { conjugate }\end{array}$ & Male Holtzman rats & $\begin{array}{l}\text { Acquisition of oxycodone } \\
\text { SA ( } 60 \mu \mathrm{g} / \mathrm{kg} / \text { infusion }), \\
\text { fixed ratio }\end{array}$ & $\downarrow$ & {$[34]$} \\
\hline Oxycodone & $\begin{array}{l}\text { Oxycodone hapten/TT } \\
\text { conjugate }\end{array}$ & Male Wistar rats & $\begin{array}{l}\text { Acquisition of oxycodone } \\
\text { SA }(60,150 \mu \mathrm{g} / \mathrm{kg} / \mathrm{infu}- \\
\text { sion), fixed ratio }\end{array}$ & $\begin{array}{l}60 \mu \mathrm{g} / \mathrm{kg} / \text { infusion: } \varnothing \\
150 \mu \mathrm{g} / \mathrm{kg} \text { /infusion: } \uparrow\end{array}$ & {$[33]$} \\
\hline \multicolumn{6}{|c|}{ Ongoing opioid self-administration } \\
\hline Heroin & $\begin{array}{l}\text { Morphine-6/hemisuccinyl- } \\
\text { bovine serum albumin } \\
\text { conjugate }\end{array}$ & Male rhesus monkey & $\begin{array}{l}\text { Ongoing heroin SA } \\
\text { (6-100 } \mu \mathrm{g} / \mathrm{kg} / \text { infusion }), \\
\text { fixed ratio }\end{array}$ & $\downarrow$ & {$[25]$} \\
\hline Heroin & $\begin{array}{l}\text { Morphine-6/hemisuccinyl- } \\
\text { bovine serum albumin } \\
\text { conjugate (passive) }\end{array}$ & Male rhesus monkey & $\begin{array}{l}\text { Ongoing heroin SA (12 } \mu \mathrm{g} / \\
\mathrm{kg} / \text { infusion), fixed ratio }\end{array}$ & $\uparrow$ & {$[26]$} \\
\hline Heroin & Morphine/TT conjugate & $\begin{array}{l}\text { Male rats (strain not dis- } \\
\text { closed) }\end{array}$ & $\begin{array}{l}\text { Ongoing heroin SA }(60 \mu \mathrm{g} / \\
\mathrm{kg} / \text { infusion), fixed ratio }\end{array}$ & $\downarrow$ & {$[41]$} \\
\hline Heroin & $\begin{array}{l}\text { Morphine hapten/KLH } \\
\text { conjugate }\end{array}$ & Male Holtzman rats & $\begin{array}{l}\text { Ongoing heroin SA } \\
\text { (3-30 } \mu \mathrm{g} / \mathrm{kg} / \text { infusion), } \\
\text { fixed ratio }\end{array}$ & $\begin{array}{l}3,10 \mu \mathrm{g} / \mathrm{kg} / \text { infusion: } \downarrow \\
6,30 \mu \mathrm{g} / \mathrm{kg} / \text { infusion: } \uparrow\end{array}$ & {$[34]$} \\
\hline Heroin & $\begin{array}{l}\text { Morphine hapten/KLH } \\
\text { conjugate }\end{array}$ & Male Holtzman rats & $\begin{array}{l}\text { Ongoing heroin }(0-30 \mu \mathrm{g} / \\
\mathrm{kg} / \text { infusion }), \text { fixed ratio }\end{array}$ & $\begin{array}{l}\text { Intake (i.e., } Q_{0} \text { ): } \downarrow \\
\text { Rate of intake change (i.e., } \\
\quad \alpha): \varnothing\end{array}$ & {$[34]$} \\
\hline Heroin & $\begin{array}{l}\text { Heroin hapten/KLH con- } \\
\text { jugate }\end{array}$ & Male Wistar rats & $\begin{array}{l}\text { Ongoing heroin SA }(60 \mu \mathrm{g} / \\
\mathrm{kg} / \text { infusion}), \text { fixed ratio, } \\
\text { progressive ratio }\end{array}$ & $\downarrow$ & {$[44]$} \\
\hline Oxycodone & $\begin{array}{l}\text { Oxycodone hapten/TT } \\
\text { conjugate }\end{array}$ & Male Wistar rats & $\begin{array}{l}\text { Ongoing oxycodone SA } \\
(60,150 \mu \mathrm{g} / \mathrm{kg} / \text { infusion }) \\
\text { fixed ratio, progressive } \\
\text { ratio }\end{array}$ & $\varnothing$ & {$[33]$} \\
\hline Fentanyl & $\begin{array}{l}\text { Fentanyl hapten/TT con- } \\
\text { jugate }\end{array}$ & $\begin{array}{l}\text { Male and female Sprague- } \\
\text { Dawley rats }\end{array}$ & $\begin{array}{l}\text { Ongoing fentanyl SA } \\
3.2 \mu \mathrm{g} / \mathrm{kg} / \text { infusion, fixed } \\
\text { ratio }\end{array}$ & $\downarrow$ & {$[47]$} \\
\hline Fentanyl & $\begin{array}{l}\text { Fentanyl hapten/TT con- } \\
\text { jugate }\end{array}$ & $\begin{array}{l}\text { Male and female Sprague- } \\
\text { Dawley rats }\end{array}$ & $\begin{array}{l}\text { Ongoing fentanyl SA ( } 0, \\
0.32-100 \mu \mathrm{g} / \mathrm{kg} / \text { infusion}), \\
\text { concurrent schedule }\end{array}$ & $\downarrow$ & {$[47]$} \\
\hline \multicolumn{6}{|c|}{ Reinstatement of opioid self-administration } \\
\hline Heroin & $\begin{array}{l}\text { Heroin hapten/KLH con- } \\
\text { jugate }\end{array}$ & Male Wistar rats & $\begin{array}{l}\text { Heroin-primed reinstate- } \\
\text { ment }(180 \mu \mathrm{g} / \mathrm{kg} \text {, intra- } \\
\text { venous })\end{array}$ & $\downarrow$ & {$[44]$} \\
\hline Heroin & $\begin{array}{l}\text { 6-Glutarylmorphine/KLH } \\
\text { conjugate }\end{array}$ & Male Sprague-Dawley rats & $\begin{array}{l}\text { Heroin-primed reinstate- } \\
\text { ment }(500 \mu \mathrm{g} / \mathrm{kg} \text {, subcu- } \\
\text { taneous })\end{array}$ & $\downarrow$ & {$[56]$} \\
\hline Heroin & $\begin{array}{l}\text { 6-Glutarylmorphine/KLH } \\
\text { conjugate }\end{array}$ & Male Sprague-Dawley rats & $\begin{array}{l}\text { Heroin-primed reinstate- } \\
\text { ment }(500 \mu \mathrm{g} / \mathrm{kg} \text {, subcu- } \\
\text { taneous })\end{array}$ & $\downarrow$ & {$[57]$} \\
\hline
\end{tabular}


Table 1 (continued)

\begin{tabular}{llllll}
\hline Drug & Vaccine & Species and sex & Primary endpoint & Main effect & References \\
\hline Heroin & $\begin{array}{l}\text { Morphine hapten/KLH } \\
\text { conjugate }\end{array}$ & Male Holtzman rats & $\begin{array}{c}\text { Heroin-primed reinstate- } \\
\text { ment }(600 \mu \mathrm{g} / \mathrm{kg}, \text { subcu- } \\
\text { taneous) }\end{array}$ & $\downarrow$ \\
\hline
\end{tabular}

$K L H$ keyhole limpet hemocyanin, $T T$ tetanus toxoid

the complete drug self-administration dose-effect function, the results from a single-unit drug dose are uninterpretable.

Thirty years since the first opioid vaccine was preclinically evaluated, next-generation vaccines are being developed and evaluated with clinically approved carrier proteins and adjuvants. For example, a morphine-tetanus toxoid (TT) vaccine decreased rates of heroin $(0.06 \mathrm{mg} / \mathrm{kg} / \mathrm{infusion})$ selfadministration under an FR schedule in rats [41]. Similar decreases in rates of heroin self-administration in rats have been reported with a morphine-keyhole limpet hemocyanin (KLH) vaccine [34]. Multiple heroin doses were examined in one study [34], and based on the dose ranges examined the vaccine produced an approximate three-fold potency shift in the heroin self-administration dose-effect function. Furthermore, these two morphine vaccines were effective in altering heroin self-administration, whereas a morphine vaccine discussed in the previous section [27] was ineffective in attenuating acquisition of heroin self-administration. The reasons for these differential morphine vaccine effects on heroin selfadministration are most likely antibody specificity and affinity for heroin, 6-acetylmorphine, and morphine. For example, the morphine vaccine in [27] resulted in antibodies that had poor affinity for heroin and 6-acetylmorphine compared with the heroin vaccine. In contrast, the morphine-TT [41] and morphine-KLH [34] vaccines showed similar specificity and affinity for heroin, 6-acetylmorphine, and morphine, respectively. Collectively, these studies highlight the challenges of targeting heroin with immunopharmacotherapies.

Evidence thus far suggests vaccines reduce the potency of opioids to maintain drug self-administration behavior. Other schedules of reinforcement, such as PR, are hypothesized to measure the reinforcing efficacy or strength of the abused drug rather than the reinforcing potency [42, 43]. Typically, under a PR schedule, the number of operant responses required to obtain a reinforcer systematically increases following each reinforcer delivery either within or between self-administration sessions. The maximum price (i.e., response requirement) that the subject emits to obtain a reinforcer is termed the "breakpoint." In one study, a heroin$\mathrm{KLH}$ vaccine decreased the breakpoint for heroin $(0.06 \mathrm{mg} /$ $\mathrm{kg} /$ infusion) relative to vehicle-treated rats [44]. However, an oxycodone-TT vaccine did not significantly decrease the breakpoint for either oxycodone dose $(0.06$ or $0.15 \mathrm{mg} / \mathrm{kg} /$ infusion) [33]. Furthermore, a morphine-KLH vaccine did not decrease behavioral economic metrics of reinforcing efficacy but did decrease metrics of reinforcing potency using a between-session dose-reduction procedure [34]. In summary, with the exception of [44], these studies do not provide compelling evidence that opioid vaccines decrease measures of reinforcing efficacy.

Another schedule of reinforcement that is hypothesized to measure reinforcing strength or efficacy is concurrent schedules or "choice" procedures. Concurrent schedules are routinely used in human laboratory drug self-administration studies $[45,46]$ evaluating candidate small-molecule medications for substance use disorder. In a recent study by our group [47], fentanyl-TT vaccine administration promoted behavioral reallocation away from fentanyl self-administration and towards food (i.e., diluted vanilla-flavored Ensure ${ }^{\circledR}$ ) by week 4 and vaccine effectiveness was sustained for at least 16 weeks. Furthermore, vaccine effectiveness was similar to continuous naltrexone treatment. Vaccine effectiveness was surmountable and $\mathrm{ED}_{50}$ value comparisons demonstrated an approximate 22 -fold potency shift in the fentanyl choice dose-effect function. Notably, the potency shift for intravenous fentanyl antinociception in a warm water tailwithdrawal procedure was qualitatively similar (15-fold) to the potency shift on fentanyl self-administration and not significantly different based on overlapping confidence limits. In conclusion, this single study provides some empirical evidence that potency shifts on antinociceptive endpoints may be predictive of potency shifts on abuse-related (i.e., self-administration) endpoints.

In the studies described above, opioid self-administration session lengths are typically short (e.g., $2 \mathrm{~h}$ ) in duration and daily opioid exposure is insufficient for rats to become opioid dependent as demonstrated by somatic withdrawal signs when opioid self-administration is terminated or an opioid antagonist is administered [48]. However, when access conditions are increased by prolonging opioid self-administration session duration (e.g., $12 \mathrm{~h}$ ), rats will become opioid dependent as confirmed by somatic withdrawal signs following opioid antagonist administration [48-51]. Two studies have evaluated vaccine effects under these experimental conditions. In one study, a heroin-KLH vaccine blocked further escalation of heroin $(0.06 \mathrm{mg} / \mathrm{kg} /$ infusion $)$ self-administration under an FR 1 schedule relative to vehicle-treated rats, although rates of self-administration did not decrease in the vaccinated rats relative to their own pre-vaccination baseline [44]. In a second cohort of rats, the experiment was 
reproduced with the exception that heroin availability was no longer signaled by visual discriminative stimuli. As in the first cohort, vehicle-treated rats escalated rates of heroin self-administration. However, the vaccinated rats exhibited an extinction-like pattern of behavior across the nine experimental sessions, suggesting that rates of self-administration in the first cohort of vaccinated rats were maintained, at least in part, by the visual discriminative stimuli. Furthermore, this pattern of extinction-like responding was also observed in a recent rat study following fentanyl-TT vaccine administration [47]. Although these results provide evidence that opioid vaccines can block escalation of opioid self-administration, the magnitude of vaccine-induced potency shifts on this endpoint remains to be empirically determined.

In summary, opioid vaccines attenuate ongoing opioid self-administration in both non-human primates and rats, providing proof-of-principle empirical validation and support for progression to human laboratory/clinical trials. Strengths of evaluating vaccine effectiveness on maintenance of opioid self-administration include (1) repeated testing within the same animal allowing for the within-subject evaluation of vaccine effectiveness time course [26, 47], (2) within-subject behavioral selectivity of vaccine effectiveness $[25,26]$, and (3) within-subject comparison with positive control and clinically used medications [26, 47]. Because many of these studies have only examined a single-unit dose of the targeted opioid (but see [25, 34, 47]), quantifying potency shifts in the opioid self-administration dose-effect function and comparisons of vaccine effectiveness across different laboratories are complicated.

\subsection{Vaccine Effects on Relapse-Related Endpoints of Drug Self-Administration}

The high rates of relapse among detoxified opioid users poses a significant barrier to long-term OUD treatment [52, 53]. Perhaps unsurprisingly, candidate OUD medications are clinically evaluated for their ability to prevent relapse, inferred through opioid-negative urine samples [54]. Preclinical relapse models, generally referred to as "reinstatement" models, have demonstrated that exposure to a variety of stimuli (e.g., the opioid itself or opioid-associated stimuli) are sufficient in provoking a relapse-like response in rats (for review, see [55]). However, studies have largely focused on vaccine effectiveness to attenuate opioid re-exposureinduced reinstatement of operant responding.

One important consideration when evaluating vaccine effectiveness on relapse-related endpoints is the timing of vaccine administration. In one study [34], rats were administered a morphine vaccine prior to heroin self-administration training. As described in Sect. 3.2, vaccinated rats had higher rates of heroin self-administration for the same unit heroin dose $(0.06 \mathrm{mg} / \mathrm{kg} /$ infusion $)$ compared with control rats. Following extinction of heroin self-administration by substituting saline for heroin, the vaccinated rats were less sensitive to the reinstating effects of non-contingent heroin $(0.5 \mathrm{mg} / \mathrm{kg}$, subcutaneous) administration compared with control rats $[56,57]$. However, the lack of a complete heroin dose-effect function precludes the ability to estimate the magnitude of this vaccine-induced potency shift. Other published studies have examined opioid vaccine effectiveness after subjects have acquired opioid self-administration. For example, a heroin - but not morphine-targeted vaccine blocked heroin- $(0.18 \mathrm{mg} / \mathrm{kg}$, intravenous $)$ primed reinstatement [44]. In addition, opioid vaccines have demonstrated some degree of durability to block opioid-induced reinstatement lasting for at least 25 days [57]. However, a heroin vaccine was ineffective in attenuating reinstatement induced by either heroin-associated audio/visual stimuli or a pharmacological stressor (e.g., yohimbine) [44]. Overall, these results provide evidence that immunopharmacotherapies primarily work on pharmacological mechanisms of drug relapse and may not be effective for drug-associated cue or stress-associated relapse conditions [58]. Moreover, the predictive validity of preclinical reinstatement procedures for candidate substance use disorder medication effectiveness has thus far been less robust compared to drug selfadministration procedures $[59,60]$.

\section{Vaccine Effects on Other Preclinical Abuse-Related Endpoints}

Although preclinical drug self-administration procedures are the predominant method to evaluate candidate medication effectiveness on abuse-related endpoints, there are other preclinical procedures that assess abuse-related endpoints. Two procedures (e.g., drug discrimination and conditioned place preference) have been used to preclinically evaluate candidate immunopharmacotherapies. The translational predictive validity of these procedures for medication effectiveness of small molecules is not as good as drug self-administration procedures [21, 61]. Thus, these procedures are included in this article towards the goal of systematically reviewing the available preclinical literature evaluating candidate immunopharmacotherapies on abuse-related endpoints and the relative advantages and disadvantages of these various approaches.

\subsection{Vaccine Effects on Drug Discrimination}

To date, there are no published studies examining opioid-targeted vaccines on abuse-related endpoints as measured using a drug discrimination procedure. However, drug discrimination procedures have been used to assess the effectiveness of other biological treatments targeted for other drugs of 
abuse such as cocaine [62, 63], methamphetamine [64, 65], and nicotine [66]. Drug discrimination procedures are typically trained by differentially reinforcing responding on one manipulandum (e.g., left lever) following an experimenteradministered drug (e.g., heroin) and a different manipulandum (e.g., right lever) following an experimenter-administered vehicle. After a sufficient number of pairings under these contingencies, a research subject will learn to respond on the injection-appropriate lever or "discriminate" based on the presence or absence of the training drug dose (for review, see $[67,68])$. The discriminative stimulus effects of drugs in laboratory animals are thought to be predictive of the abuserelated subjective effects in humans (e.g., [69]). Similar to antinociception procedures described above, drug discrimination procedures offer several experimental advantages such as the ability to conduct within-session dose-effect functions that allow for the assessment of potency shifts over time following immunopharmacotherapy administration.

For example, the effectiveness and selectivity of a nanoparticle-based nicotine vaccine was determined using a nicotine drug discrimination procedure in squirrel monkeys [66]. The nicotine vaccine significantly attenuated the discriminative stimulus effects of the training nicotine dose, but not the structurally dissimilar nicotinic agonist (+)-epibatidine over experimental weeks 19-22. Furthermore, when complete dose-effect functions were determined post-vaccine administration, the vaccine shifted the potency of nicotine approximately three-fold compared to a pre-vaccine baseline without altering the potency of either (+)-epibatidine or the partial nicotinic agonist varenicline. In another example, a mutant cocaine esterase produced dose- and time-dependent shifts in discriminative stimulus potency of cocaine with maximal potency shifts of greater than 50-fold observed both immediately after and $24 \mathrm{~h}$ following cocaine esterase administration to rats [62]. Although drug discrimination endpoints allow for the assessment of potency shifts on abuse-related endpoints over relatively long experimental timelines, one translational complication is that candidate treatments that have attenuated the abuse-related subjective effects have not retained effectiveness when evaluated in either human laboratory drug self-administration procedures or clinical trials [20].

\subsection{Vaccination Effects on Conditioned Place Preference}

Place conditioning procedures are commonly used in the preclinical assessment of abuse liability [70]. These procedures leverage the ability of drugs of abuse to produce learned (i.e., Pavlovian) associations with contextual nondrug stimuli [71] as an index of abuse liability. A basic place conditioning apparatus comprises two chambers differentiated by visual, olfactory, and tactile stimuli. During the experimental conditioning phase, the research subject is administered an opioid (e.g., heroin injection) before being confined to one of the chambers. In a subsequent conditioning session on the same day, the subject is administered a vehicle (e.g., saline injection) before being confined to the opposite chamber. Following a number of pairings of the opioid and vehicle with their respective chambers, the subject is allowed concurrent access to both chambers in a drugfree state on a separate test day. The relative amount of time spent in the drug-paired chamber is typically utilized as the main dependent measure. The hypothesis is that an attenuation of opioid-induced place preference reflects a decrease in context-induced drug craving and has been argued to translate to a reduced likelihood of relapse (see [72] for review).

The effects of vaccination on opioid-conditioned place preference have been reported in two studies. In one study, the effectiveness of a heroin- and morphine-targeted vaccine was determined in rats [44]. A single dose $(0.4 \mathrm{mg} / \mathrm{kg})$ of heroin and morphine produced a place preference in nonvaccinated rats. Heroin vaccine administration before heroin or morphine conditioning blocked the expression of heroin or morphine place preference. In contrast, the morphine vaccine selectively blocked the expression of morphine, but not heroin, place preference. These results were interpreted to suggest that vaccines should target the prodrug heroin rather than the active metabolite morphine. In a different study, a morphine-targeted vaccine blocked the expression of morphine-induced place preference at two different doses 1 and $2 \mathrm{mg} / \mathrm{kg}$ [73]. In summary, these two studies provide evidence that opioid-targeted vaccines can decrease the ability of opioids to function as conditioned stimuli similar to the opioid antagonist naltrexone $[74,75]$.

However, these conditioned place preference results also highlight potential limitations of this approach for the preclinical evaluation of opioid-targeted vaccines. First, the most significant limitation is that the experimental subject can only be tested once and thus a significant number of animals would be needed to conduct well-controlled and designed experiments. Thus, separate groups of animals would be required for each drug dose and each experimental condition (e.g., active vs control vaccine). For example, in the two studies described above evaluating vaccine effects on opioid-induced place preference [44,73], only one or two opioid doses were tested in both active vaccine and control animals. Without a complete dose-effect function of the opioid agonist under both active vaccine and control conditions, inferences regarding vaccine effectiveness to produce clinically relevant potency shifts in the target opioid agonist are difficult to make. In addition, to determine vaccine selective for the target opioid compared to structurally dissimilar opioid agonists, separate groups of animals would also be required for each structurally dissimilar opioid agonist dose and experimental condition. 
A second limitation of using conditioned place preference procedures to evaluate vaccine effectiveness is the selection of what time point to evaluate vaccine effectiveness relative to vaccine administration. In one study, opioid conditioning occurred across 4 days that were hypothesized to be during the peak time of vaccine effectiveness [44]. However, in the other study, morphine conditioning days occurred during weeks 4-6 of the vaccination regimen, although peak antibody titer levels were not observed until week 18 [73]. Regardless, the evaluation of vaccine effectiveness over time would require separate groups of animals and invoking the first limitation described above.

In summary, evidence from two preclinical studies demonstrate opioid vaccines can decrease the ability of the targeted opioid to produce a conditioned place preference. However, evaluation of potency shifts, time course, and selectivity of vaccine effectiveness would require a significant number of subjects relative to drug discrimination, drug self-administration, or antinociception measures. This requirement for large animal numbers decreases the efficiency of this procedure to evaluate vaccine effectiveness and has contributed to the relative infrequent use of this procedure relative to other preclinical procedures. Moreover, conditioned place preference procedures are less reliable than self-administration as behavioral assays for evaluating candidate OUD medications. This poor reliability of conditioned place preference procedures parallels the poor reliability of subjective measures in human laboratory studies vs self-administration procedures to assess candidate substance use disorder medications $[20,21]$.

\section{Conclusions and Future Directions}

Although naltrexone, buprenorphine, and methadone are clinically available OUD treatments, their utility is limited by either poor patient compliance (e.g., depot naltrexone) or abuse liability concerns (e.g., buprenorphine and methadone). Preclinical research, to date, has provided "proof of concept" empirical evidence that some opioid-targeted vaccines (e.g., fentanyl-TT) produced potency shifts on both opioid antinociceptive and abuse-related endpoints similar to naltrexone or buprenorphine maintenance. These immunopharmacotherapies should be prioritized for continued development and evaluation in humans to provide clinicians with additional therapeutic options and reverse translational feedback on preclinical endpoints.

To date, two different vaccines for substance use disorder have been promoted to clinical trials. Vaccines for both nicotine and cocaine have failed to demonstrate effectiveness on primary endpoints in humans (for review, see [76, 77]). Given these clinical trial failures, how should preclinical research proceed in evaluating immunopharmacotherapy effectiveness for OUD or other substance use disorders to enhance translatability of preclinical results to clinical testing? We propose four preclinical experimental design attributes and a potential algorithm (Fig. 1) to guide future preclinical vaccine development research and enhance preclinical-to-clinical translatability.

First, vaccine effectiveness should be evaluated under experimental conditions where opioids and other target drugs of abuse are administered intravenously. Although initial prescription opioid misuse often starts via the oral route by consuming tablets, opioid use has been shown to transition to injection routes for both continued prescription opioids [78] and heroin [79]. In addition, emerging evidence suggests that vaccine effectiveness may depend on the route of administration, such that opioid vaccines are less effective against intravenously administered opioid agonists [80-82]. The working hypothesis is that subcutaneous or intraperitoneal administered opioids allow for a greater opportunity for antibody/opioid interactions compared to intravenous opioid administration. We recognize the practical and technical challenges of implanting and maintaining intravenous catheters in animals. Thus, initial vaccine characterization and optimization could be accomplished via a non-intravenous route of administration (e.g., subcutaneous, intraperitoneal, or oral) before later stage preclinical validation of vaccine effectiveness against intravenously administered opioids (Fig. 1). This approach would generate an experimental range or index of vaccine effectiveness.

Second, preclinical candidate vaccine effectiveness should be evaluated in terms of potency shifts compared to

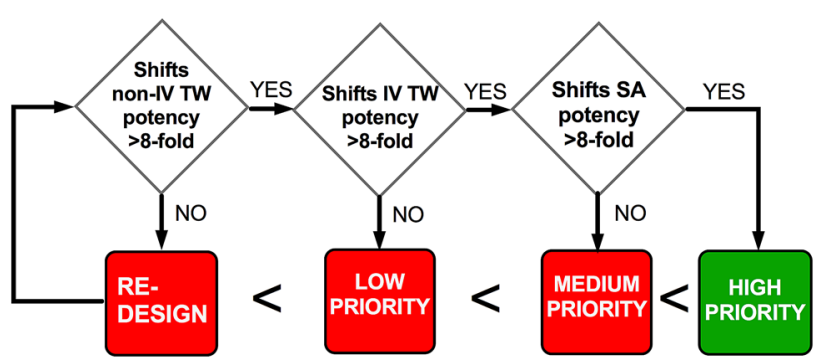

Fig. 1 Proposed preclinical algorithm to evaluate candidate immunopharmacotherapies for opioid use disorder treatment. Immunopharmacotherapies would be evaluated through a series of stages that are initially sensitive (e.g., Stages 1 and 2: are potency shifts in opioid antinociception [e.g., tail withdrawal: TW] where the opioid was administered non-intravenously [IV, e.g., subcutaneously, intraperitoneally, or orally] and IV observed following vaccine administration?) and become progressively more selective (e.g., Stage 3: potency shifts on intravenous opioid self-administration [SA]). Candidate immunopharmacotherapies that are effective through all stages would have the highest priority for clinical evaluation as candidate opioid use disorder medications. Candidate immunopharmacotherapies that reach the low- or medium-priority stage may have clinical utility on harm reduction endpoints (e.g., lower rates of fatalities) but would require further preclinical and clinical evaluation on those endpoints 
either a pre-vaccination baseline or control vaccine group on either opioid antinociceptive or drug self-administration endpoints. The use of potency shifts as a primary dependent measure to assess vaccine effectiveness offers two main experimental and interpretative advantages. First, potency shifts enhance experimental rigor and allow for appropriate comparisons with positive controls. For example, human laboratory studies have demonstrated that clinically effective depot naltrexone formulations produce at least an eightfold potency shift in the opioid agonist dose-effect function [83]. Similar potency shifts have also been reported with buprenorphine [84-86]. In preclinical studies, continuous naltrexone administration via an osmotic pump or continuous intravenous infusion are methods to mimic these clinically used depot naltrexone or buprenorphine formulations. Under these experimental conditions, naltrexone produced at least eight-fold potency shifts in opioid agonist dose-effect functions at clinically effective plasma naltrexone concentrations in both rats [81] and monkeys [87]. We propose an eight-fold potency shift "naltrexone benchmark" provides an empirical threshold to assess whether a candidate vaccine would be as effective as a medication currently in clinical use for OUD. For secondary endpoints associated with harm reduction from either intentional or unintentional opioid abuse, there is not enough empirical preclinical or clinical data to suggest whether an eight-fold potency shift is necessary for these endpoints. The degree to which candidate therapeutics might improve patient outcomes on endpoints other than abstinence is an emerging topic [54]. Second, potency shifts would allow for quantitative comparisons between different vaccine formulations both within and across research programs to guide future vaccine development work. If the ultimate goal is to develop a clinically viable therapeutic for OUD, then potency shifts provide quantitative information for industry and government leadership to make informed decisions about which immunopharmacotherapies to move from preclinical to clinical evaluations.

Third, the selection of the research subject should be thoughtfully considered and ideally vaccine effectiveness would be evaluated in both a rodent (e.g., mouse or rat) and non-human primates (e.g., rhesus monkey). Emerging empirical evidence from our research group $[18,29]$ and others [88] suggests that vaccine effectiveness may slightly diminish when translating vaccine effects from rodent to non-human primates. Thus, one proposed strategy would be to identify and optimize vaccine components in rodents and then promote the most promising vaccines to further testing in non-human primates. Vaccines that were effective in both rodents and non-human primates should be prioritized for further clinical testing.

Fourth, the time course of preclinical vaccine effectiveness on the behavioral endpoint should be evaluated and preferably in the same experimental animals. This experimental design attribute offers two advantages that should facilitate efficient preclinical immunopharmacotherapy evaluation and enhance translatability to clinical effectiveness. First, when vaccine effectiveness on the behavioral endpoint is combined with other measures of antibody titers/levels or antibody affinity, correlations can be conducted to make predictions about threshold antibody levels and antibody longevity [18, 29, 47]. Second, these types of experimental designs would allow for improved mechanistic insights into individual differences in antibody titers and affinity that could be used to improve clinical vaccine effectiveness. Notably, these individual differences in vaccine effectiveness seem to be more pronounced in non-human primates. Our working hypothesis is a more rigorous preclinical evaluation of immunopharmacotherapies as described in this article and will be more efficient and less costly in the long term for developing a clinically viable OUD vaccine.

Finally, the dynamic illicit drug environment poses several potential challenges to the clinical utility of immunopharmacotherapy as stand-alone therapeutics. For example, novel fentanyl-related substances are continuing to emerge $[89,90]$. Published fentanyl vaccines have cross-reactivity with some known fentanyl analogs [91]. In addition, illicit substances such as heroin are being adulterated with fentanyl [92]. Thus, one emerging future direction is combination or dual-vaccine therapeutics [93-95]. Furthermore, because of the specificity engendered by immunopharmacotherapies, these candidate therapeutics could potentially be combined with current clinical OUD medications. Our perspective is the combination of an immunopharmacotherapy with an existing OUD medication is the most likely clinical path forward. The rigorous preclinical evaluation of these novel immunopharmacotherapies using the strategies highlighted in this article should efficiently identify the most promising candidate immunopharmacotherapies to treat human suffering associated with the ongoing opioid crisis.

Author Contributions EAT drafted the initial manuscript version. MLB provided editorial revision. Both authors contributed to manuscript writing and approved the final version submitted for publication.

\section{Compliance with Ethical Standards}

Funding Research was supported by the National Institute on Drug Abuse of the National Institutes of Health under Award Numbers UH3DA041146 and F32DA047026. The National Institute on Drug Abuse had no role in the study design, collection, analysis or interpretation of the data, and in the writing or decision to submit the manuscript for publication. The content of the article is solely the responsibility of the authors and does not necessarily reflect the official views of the National Institutes of Health. 
Conflict of interest E Andrew Townsend and Matthew L. Banks have no biomedical financial interests or potential conflicts of interest that are directly relevant to the content of this article.

\section{References}

1. United Nations. World drug report. Geneva: United Nations; 2019.

2. Bell J, Strang J. Medication treatment of opioid use disorder. Biol Psychiatry. 2020;87(1):82-8.

3. National Academies of Sciences, Engineering, and Medicine. 2019. Medications for Opioid Use Disorder Save Lives. Washington, DC: The National Academies Press. https://doi.org/10.17226 125310 .

4. Herget G. Methadone and buprenorphine added to the WHO list of essential medicines. HIV AIDS Policy Law Rev. 2005;10(3):23-4.

5. Wightman RS, Nelson LS, Lee JD, Fox LM, Smith SW. Severe opioid withdrawal precipitated by Vivitrol ${ }^{\circledR}$. Am J Emerg Med. 2018;36(6):1128e1-2.

6. Nunes EV, Bisaga A, Krupitsky E, Nangia N, Silverman BL, Akerman SC, et al. Opioid use and dropout from extended-release naltrexone in a controlled trial: implications for mechanism. Addiction. 2020;115(2):239-46.

7. Daniulaityte R, Nahhas RW, Silverstein S, Martins S, Zaragoza A, Moeller A, et al. Patterns of non-prescribed buprenorphine and other opioid use among individuals with opioid use disorder: a latent class analysis. Drug Alcohol Depend. 2019;204:107574.

8. Jones CM, Baldwin GT, Manocchio T, White JO, Mack KA. Trends in methadone distribution for pain treatment, methadone diversion, and overdose deaths-United States, 2002-2014. MMWR Morb Mortal Wkly Rep. 2016;65(26):667-71.

9. Negus SS. Choice between heroin and food in nondependent and heroin-dependent rhesus monkeys: effects of naloxone, buprenorphine, and methadone. J Pharmacol Exp Ther. 2006;317(2):711-23.

10. Bremer PT, Janda KD. Conjugate vaccine immunotherapy for substance use disorder. Pharmacol Rev. 2017;69(3):298-315.

11. Ohia-Nwoko O, Kosten TA, Haile CN. Animal models and the development of vaccines to treat substance use disorders. Int Rev Neurobiol. 2016;126:263-91.

12. Banks ML, Olson ME, Janda KD. Immunopharmacotherapies for treating opioid use disorder. Trends Pharmacol Sci. 2018;39(11):908-11.

13. Johnson S, North R. Opioids excite dopamine neurons by hyperpolarization of local interneurons. J Neurosci. 1992;12(2):483-8.

14. Corre J, van Zessen R, Loureiro M, Patriarchi T, Tian L, Pascoli V, et al. Dopamine neurons projecting to medial shell of the nucleus accumbens drive heroin reinforcement. eLife. 2018;7:e39945.

15. Caruso FS, Gordon M, Pachter IJ. Methadone and naloxone in combination (Naldone) for the treatment of heroin addicts. Proc Natl Conf Methadone Treat. 1973;2:1336-41.

16. Baehr C, Pravetoni M. Vaccines to treat opioid use disorders and to reduce opioid overdoses. Neuropsychopharmacology. 2019;44(1):217-8

17. Dykstra LA, Woods JH. A tail withdrawal procedure for assessing analgesic activity in rhesus monkeys. J Pharmacol Methods. 1986;15(3):263-9.

18. Tenney RD, Blake S, Bremer PT, Zhou B, Hwang CS, Poklis JL, et al. Vaccine blunts fentanyl potency in male rhesus monkeys. Neuropharmacology. 2019;158:107730.

19. Torten M, Miller CH, Eisele JH, Henderson GL, Benjamini E. Prevention of the effects of fentanyl by immunological means. Nature. 1975;253(5492):565-6.
20. Haney M, Spealman R. Controversies in translational research: drug self-administration. Psychopharmacology. 2008;199(3):403-19.

21. Czoty PW, Stoops WW, Rush CR. Evaluation of the "pipeline" for development of medications for cocaine use disorder: a review of translational preclinical, human laboratory, and clinical trial research. Pharmacol Rev. 2016;68(3):533-62.

22. Mello NK, Negus SS. Preclinical evaluation of pharmacotherapies for treatment of cocaine and opioid abuse using drug self-administration procedures. Neuropsychopharmacology. 1996;14(6):375-424.

23. Banks ML, Negus SS. Insights from preclinical choice models on treating drug addiction. Trends Pharmacol Sci. 2017;38:181-94.

24. Skinner B. The behavior of organisms. New York: AppletonCentury-Crofts; 1938.

25. Bonese KF, Wainer BH, Fitch FW, Rothberg RM, Schuster CR. Changes in heroin self-administration by a rhesus monkey after morphine immunisation. Nature. 1974;252(5485):708-10.

26. Killian A, Bonese K, Rothberg RM, Wainer BH, Schuster CR. Effects of passive immunization against morphine on heroin selfadministration. Pharmacol Biochem Behav. 1978;9(3):347-52.

27. Stowe GN, Vendruscolo LF, Edwards S, Schlosburg JE, Misra $\mathrm{KK}$, Schulteis G, et al. A vaccine strategy that induces protective immunity against heroin. J Med Chem. 2011;54(14):5195-204.

28. Gottås A, Øiestad EL, Boix F, Vindenes V, Ripel Å, Thaulow $\mathrm{CH}$, et al. Levels of heroin and its metabolites in blood and brain extracellular fluid after i.v. heroin administration to freely moving rats. Br J Pharmacol. 2013;170(3):546-56.

29. Bremer PT, Schlosburg JE, Banks ML, Steele FF, Zhou B, Poklis JL, et al. Development of a clinically viable heroin vaccine. J Am Chem Soc. 2017;139(25):8601-11.

30. Inturrisi CE, Max MB, Foley KM, Schultz M, Shin S-U, Houde $\mathrm{RW}$. The pharmacokinetics of heroin in patients with chronic pain. N Engl J Med. 1984;310(19):1213-7.

31. Boerner U. The metabolism of morphine and heroin in man. Drug Metab Rev. 1975;4(1):39-73.

32. Pravetoni M, Pentel PR, Potter DN, Chartoff EH, Tally L, LeSage MG. Effects of an oxycodone conjugate vaccine on oxycodone self-administration and oxycodone-induced brain gene expression in rats. PLoS One. 2014;9(7):e101807.

33. Nguyen JD, Hwang CS, Grant Y, Janda KD, Taffe MA. Prophylactic vaccination protects against the development of oxycodone self-administration. Neuropharmacology. 2018;138:292-303.

34. Raleigh MD, Pentel PR, LeSage MG. Pharmacokinetic correlates of the effects of a heroin vaccine on heroin self-administration in rats. PLoS One. 2014;9(12):e115696.

35. Negus SS, Henriksen SJ, Mattox A, Pasternak GW, Portoghese PS, Takemori AE, et al. Effect of antagonists selective for mu, delta and kappa opioid receptors on the reinforcing effects of heroin in rats. J Pharmacol Exp Ther. 1993;265(3):1245-52.

36. Venniro M, Zhang M, Caprioli D, Hoots JK, Golden SA, Heins $\mathrm{C}$, et al. Volitional social interaction prevents drug addiction in rat models. Nat Neurosci. 2018;21(11):1520-9.

37. Alexander BK, Beyerstein BL, Hadaway PF, Coambs RB. Effect of early and later colony housing on oral ingestion of morphine in rats. Pharmacol Biochem Behav. 1981;15(4):571-6.

38. Lynch WJ, Carroll ME. Regulation of drug intake. Exp Clin Psychopharmacol. 2001;9(2):131-43.

39. Negus SS, Banks ML. Making the right choice: lessons from drug discrimination for research on drug reinforcement and drug self-administration. In: Glennon RA, Young R, editor. Drug discrimination. Hoboken, NJ: Wiley; 2011. p. 361-88. https://doi. org/10.1002/9781118023150.ch11.

40. Banks ML, Negus SS. Preclinical determinants of drug choice under concurrent schedules of drug self-administration. Adv Pharmacol Sci. 2012;2012:281768. 
41. Anton B, Leff P. A novel bivalent morphine/heroin vaccine that prevents relapse to heroin addiction in rodents. Vaccine. 2006;24(16):3232-40.

42. Hodos W. Progressive ratio as a measure of reward strength. Science. 1961;134(3483):943-4.

43. Richardson NR, Roberts DC. Progressive ratio schedules in drug self-administration studies in rats: a method to evaluate reinforcing efficacy. J Neurosci Methods. 1996;66(1):1-11.

44. Schlosburg JE, Vendruscolo LF, Bremer PT, Lockner JW, Wade CL, Nunes AA, et al. Dynamic vaccine blocks relapse to compulsive intake of heroin. Proc Natl Acad Sci USA. 2013;110(22):9036-41.

45. Jones JD, Bisaga A, Metz VE, Manubay JM, Mogali S, Ciccocioppo R, et al. The PPARgamma agonist pioglitazone fails to alter the abuse potential of heroin, but does reduce heroin craving and anxiety. J Psychoact Drugs. 2018;50(5):390-401.

46. Lile JA, Johnson AR, Banks ML, Hatton KW, Hays LR, Nicholson $\mathrm{KL}$, et al. Pharmacological validation of a translational model of cocaine use disorder: effects of d-amphetamine maintenance on choice between intravenous cocaine and a nondrug alternative in humans and rhesus monkeys. Exp Clin Psychopharmacol. 2019. https://doi.org/10.1037/pha0000302 (Epub ahead of print).

47. Townsend EA, Blake S, Faunce KE, Hwang CS, Natori Y, Zhou B, et al. Conjugate vaccine produces long-lasting attenuation of fentanyl vs. food choice and blocks expression of opioid withdrawalinduced increases in fentanyl choice in rats. Neuropsychopharmacology. 2019;44(10):1681-9.

48. Towers EB, Tunstall BJ, McCracken ML, Vendruscolo LF, Koob GF. Male and female mice develop escalation of heroin intake and dependence following extended access. Neuropharmacology. 2019;151:189-94.

49. Chen SA, O'Dell LE, Hoefer ME, Greenwell TN, Zorrilla EP, Koob GF. Unlimited access to heroin self-administration: independent motivational markers of opiate dependence. Neuropsychopharmacology. 2006;31(12):2692-707.

50. Wade CL, Vendruscolo LF, Schlosburg JE, Hernandez DO, Koob GF. Compulsive-like responding for opioid analgesics in rats with extended access. Neuropsychopharmacology. 2015;40(2):421-8.

51. Ahmed SH, Walker JR, Koob GF. Persistent increase in the motivation to take heroin in rats with a history of drug escalation. Neuropsychopharmacology. 2000;22(4):413-21.

52. Hunt WA, Barnett LW, Branch LG. Relapse rates in addiction programs. J Clin Psychol. 1971;27(4):455-6.

53. US Food and Drug Administration. The voice of the patient: opioid use disorder. Center for Drug Evaluation and Research Patient-focused Drug Development Initiative; 2018. https://www. fda.gov/media/124391/download. Accessed 11 Nov 2019.

54. Volkow ND, Woodcock J, Compton WM, Throckmorton DC, Skolnick P, Hertz S, et al. Medication development in opioid addiction: meaningful clinical end points. Sci Transl Med. 2018. https://doi.org/10.1126/scitranslmed.aan2595.

55. Reiner DJ, Fredriksson I, Lofaro OM, Bossert JM, Shaham Y. Relapse to opioid seeking in rat models: behavior, pharmacology and circuits. Neuropsychopharmacology. 2019;44(3):465-77.

56. Li Q-Q, Luo Y-X, Sun C-Y, Xue Y-X, Zhu W-L, Shi H-S, et al. A morphine/heroin vaccine with new hapten design attenuates behavioral effects in rats. J Neurochem. 2011;119(6):1271-81.

57. Li Q-Q, Sun C-Y, Luo Y-X, Xue Y-X, Meng S-Q, Xu L-Z, et al. A conjugate vaccine attenuates morphine- and heroin-induced behavior in rats. Int $\mathbf{J}$ Neuropsychopharmacol. 2015;18(5):pii:pyu093.

58. Tunstall BJ, Vendruscolo LF. Utility of fentanyl vaccines: unique challenges posed by preventing opioid overdose and treating opioid use disorder. Neuropsychopharmacology. 2019:44(10):1675-6.
59. Katz JL, Higgins ST. The validity of the reinstatement model of craving and relapse to drug use. Psychopharmacology. 2003;168(1):21-30.

60. Epstein DH, Preston KL, Stewart J, Shaham Y. Toward a model of drug relapse: an assessment of the validity of the reinstatement procedure. Psychopharmacology. 2006;189(1):1-16.

61. Comer SD, Ashworth JB, Foltin RW, Johanson CE, Zacny JP, Walsh SL. The role of human drug self-administration procedures in the development of medications. Drug Alcohol Depend. 2008;96(1-2):1-15.

62. Collins GT, Narasimhan D, Cunningham AR, Zaks ME, Nichols J, Ko M-C, et al. Long-lasting effects of a PEGylated mutant cocaine esterase (CocE) on the reinforcing and discriminative stimulus effects of cocaine in rats. Neuropsychopharmacology. 2012;37(5):1092-103.

63. Schindler CW, Justinova Z, Lafleur D, Woods D, Roschke V, Hallak H, et al. Modification of pharmacokinetic and abuse-related effects of cocaine by human-derived cocaine hydrolase in monkeys. Addict Biol. 2013;18(1):30-9.

64. McMillan DE, Hardwick WC, Li M, Owens SM. Pharmacokinetic antagonism of (+)-methamphetamine discrimination by a low-affinity monoclonal anti-methamphetamine antibody. Behav Pharmacol. 2002;13(5-6):465-73.

65. Daniels JR, Wessinger WD, Hardwick WC, Li M, Gunnell MG, Hall CJ, et al. Effects of anti-phencyclidine and anti-(+)-methamphetamine monoclonal antibodies alone and in combination on the discrimination of phencyclidine and (+)-methamphetamine by pigeons. Psychopharmacology. 2006;185(1):36-44.

66. Desai RI, Bergman J. Effects of the nanoparticle-based vaccine, SEL-068, on nicotine discrimination in squirrel monkeys. Neuropsychopharmacology. 2015;40(9):2207-16.

67. Holtzman SG. Drug discrimination studies. Drug Alcohol Depend. 1985;14(3-4):263-82.

68. Solinas M, Panlilio LV, Justinova Z, Yasar S, Goldberg SR. Using drug-discrimination techniques to study the abuse-related effects of psychoactive drugs in rats. Nat Protoc. 2006;1(3):1194-206.

69. Shannon HE, Holtzman SG. Evaluation of the discriminative effects of morphine in the rat. J Pharmacol Exp Ther. 1976;198(1):54-65.

70. Tzschentke TM. Measuring reward with the conditioned place preference (CPP) paradigm: update of the last decade. Addict Biol. 2007;12(3-4):227-462.

71. Pavlov IP, Anrep GV. Conditioned reflexes; an investigation of the physiological activity of the cerebral cortex. London: Oxford University Press, Humphrey Milford; 1927.

72. Napier TC, Herrold AA, de Wit H. Using conditioned place preference to identify relapse prevention medications. Neurosci Biobehav Rev. 2013;37(9 Pt A):2081-6.

73. Kosten TA, Shen XY, O'Malley PW, Kinsey BM, Lykissa ED, Orson FM, et al. A morphine conjugate vaccine attenuates the behavioral effects of morphine in rats. Prog Neuropsychopharmacol Biol Psychiatry. 2013;45:223-9.

74. Olmstead MC, Burns LH. Ultra-low-dose naltrexone suppresses rewarding effects of opiates and aversive effects of opiate withdrawal in rats. Psychopharmacology. 2005;181(3):576-81.

75. Bilsky EJ, Marglin SH, Reid LD. Using antagonists to assess neurochemical coding of a drug's ability to establish a conditioned place preference. Pharmacol Biochem Behav. 1990;37(3):425-31.

76. Heekin RD, Shorter D, Kosten TR. Current status and future prospects for the development of substance abuse vaccines. Exp Rev Vaccines. 2017;16(11):1067-77.

77. Skolnick P. Biologic approaches to treat substance-use disorders. Trends Pharmacol Sci. 2015;36(10):628-35.

78. Lake S, Milloy MJ, Dong H, Hayashi K, Wood E, Kerr T, et al. Initiation into prescription opioid injection and associated trends 
in heroin use among people who use illicit drugs. Drug Alcohol Depend. 2016;169:73-9.

79. Monico LB, Mitchell SG. Patient perspectives of transitioning from prescription opioids to heroin and the role of route of administration. Subst Abuse Treat Prev Policy. 2018;13(1):4.

80. Raleigh MD, Laudenbach M, Baruffaldi F, Peterson SJ, Roslawski MJ, Birnbaum AK, et al. Opioid dose- and route-dependent efficacy of oxycodone and heroin vaccines in rats. J Pharmacol Exp Ther. 2018;365(2):346-53.

81. Schwienteck KL, Blake S, Bremer PT, Poklis JL, Townsend EA, Negus SS, et al. Effectiveness and selectivity of a heroin conjugate vaccine to attenuate heroin, 6-acetylmorphine, and morphine antinociception in rats: comparison with naltrexone. Drug Alcohol Depend. 2019;204:107501.

82. Sulima A, Jalah R, Antoline JFG, Torres OB, Imler GH, Deschamps JR, et al. A stable heroin analogue that can serve as a vaccine hapten to induce antibodies that block the effects of heroin and its metabolites in rodents and that cross-react immunologically with related drugs of abuse. J Med Chem. 2018;61(1):329-43.

83. Sullivan MA, Vosburg SK, Comer SD. Depot naltrexone: antagonism of the reinforcing, subjective, and physiological effects of heroin. Psychopharmacology. 2006;189(1):37-46.

84. Comer SD, Hart CL, Ward AS, Haney M, Foltin RW, Fischman MW. Effects of repeated oral methamphetamine administration in humans. Psychopharmacology. 2001;155(4):397-404.

85. Comer SD, Walker EA, Collins ED. Buprenorphine/naloxone reduces the reinforcing and subjective effects of heroin in heroindependent volunteers. Psychopharmacology. 2005;181(4):664-75.

86. Greenwald MK, Schuh KJ, Hopper JA, Schuster CR, Johanson C-E. Effects of buprenorphine sublingual tablet maintenance on opioid drug-seeking behavior by humans. Psychopharmacology. 2002;160(4):344-52.
87. Townsend EA, Negus SS, Poklis JL, Banks ML. Lorcaserin maintenance fails to attenuate heroin vs. food choice in rhesus monkeys. Drug Alcohol Depend. 2020;208:107848.

88. Evans SM, Foltin RW, Hicks MJ, Rosenberg JB, De BP, Janda $\mathrm{KD}$, et al. Efficacy of an adenovirus-based anti-cocaine vaccine to reduce cocaine self-administration and reacqusition using a choice procedure in rhesus macaques. Pharmacol Biochem Behav. 2016;150-151:76-86.

89. Varshneya NB, Walentiny DM, Moisa LT, Walker TD, Akinfiresoye LR, Beardsley PM. Opioid-like antinociceptive and locomotor effects of emerging fentanyl-related substances. Neuropharmacology. 2019;151:171-9.

90. Walentiny DM, Moisa LT, Beardsley PM. Oxycodone-like discriminative stimulus effects of fentanyl-related emerging drugs of abuse in mice. Neuropharmacology. 2019;150:210-6.

91. Bremer PT, Kimishima A, Schlosburg JE, Zhou B, Collins KC, Janda KD. Combatting synthetic designer opioids: a conjugate vaccine ablates lethal doses of fentanyl class drugs. Angew Chem Int Ed. 2016;55(11):3772-5.

92. Buresh M, Genberg BL, Astemborski J, Kirk GD, Mehta SH. Recent fentanyl use among people who inject drugs: results from a rapid assessment in Baltimore, Maryland. Int J Drug Policy. 2019;74:41-6.

93. Hwang CS, Smith LC, Natori Y, Ellis B, Zhou B, Janda KD. Efficacious vaccine against heroin contaminated with fentanyl. ACS Chem Neurosci. 2018;9(6):1269-75.

94. Hwang CS, Smith LC, Natori Y, Ellis B, Zhou B, Janda KD. Improved admixture vaccine of fentanyl and heroin hapten immunoconjugates: antinociceptive evaluation of fentanyl-contaminated heroin. ACS Omega. 2018;3(9):11537-43.

95. Natori Y, Hwang CS, Lin L, Smith LC, Zhou B, Janda KD. A chemically contiguous hapten approach for a heroin-fentanyl vaccine. Beilstein J Org Chem. 2019;15:1020-31. 